INFLAMMATION

\title{
Lymphocytic colitis: a retrospective clinical study of 199 Swedish patients
}

\author{
M Olesen, S Eriksson, J Bohr, G Järnerot, C Tysk
}

Gut 2004;53:536-541. doi: 10.1136/gut.2003.023440

See end of article for authors' affiliations ......................

Correspondence to: Associate Professor C Tysk, Department of Medicine, Division of Gastroenterology, Örebro University Hospital, 70185 Örebro, Sweden; curt.tysk@orebroll.se

Accepted for publication 28 October 2003
Background: Lymphocytic colitis is characterised by chronic diarrhoea and specific microscopic changes in a macroscopically normal colonic mucosa. We report clinical features and treatment outcome in a large patient cohort.

Methods: Patients were searched for in 24 Swedish gastroenterology clinics. The biopsy material was reassessed using strict histopathological criteria. Clinical data were obtained from medical notes.

Results: Lymphocytic colitis was diagnosed in 199 cases. The female:male ratio was 2.4:1. Median age at diagnosis was 59 (48-70) years. The most frequent symptoms were diarrhoea (96\%), abdominal pain $(47 \%)$, and weight loss $(41 \%)$. The course was chronic intermittent in $30 \%$ of patients, chronic continuous in $7 \%$, and a single attack in $63 \%$, and in these cases the disease duration was $6(4-11)$ months. Seventy nine $(40 \%)$ patients reported associated diseases, of which thyroid disorders, coeliac disease, and diabetes mellitus were the most common. In 34 first or second degree relatives of $24(12 \%)$ patients, a family history of ulcerative colitis, Crohn's disease, collagenous colitis, or coeliac disease was reported. Drug induced disease was suspected in $19(10 \%)$ patients. A non-significant peak of disease onset was seen in December-January. More than $80 \%$ of treated patients improved on corticosteroids, including budesonide.

Conclusions: A family history of other bowel disorders is a new finding. The sudden onset and single attack of limited duration may support a possible infectious cause in some cases. Drugs may cause lymphocytic colitis.

\section{L} ymphocytic colitis (LC), first described by Lazenby et al in 1989, ${ }^{1}$ belongs, together with collagenous colitis (CC), to -the group of microscopic colitides (MC). The diagnosis of LC relies on microscopic assessment of colonic mucosal biopsies where characteristic abnormalities are found in a macroscopically normal or near normal colonic mucosa. ${ }^{12}$ Since the first report 15 years ago, data on epidemiology, ${ }^{3-5}$ clinical features, and therapy ${ }^{6-14}$ have emerged during the last few years. However, most clinical reports have been small, involving 10-80 patients, ${ }^{6-12} 14$ and only one large study with 170 cases has been published. ${ }^{13}$ Our aim is to report a retrospective study of clinical characteristics and treatment outcome in a large cohort of Swedish patients with LC.

\section{MATERIAL AND METHODS \\ Patients}

Twenty four Swedish hospitals (three university hospitals) contributed to the study. After obtaining patient consent, medical records, slides of colonic mucosa biopsy specimens, and paraffin embedded biopsies of LC patients were submitted to us. The study was approved by the ethics committee at the Örebro University Hospital.

\section{Diagnostic criteria}

We used the following histopathological criteria for LC:

- Intraepithelial lymphocytes (IEL) $\geqslant 20$ per 100 surface epithelial cells.

- Epithelial damage such as flattening and mucin depletion.

- Inflammation in the lamina propria with mainly mononuclear cells.

- A subepithelial collagen layer $<10 \mu \mathrm{m}$.

Colonoscopy with multiple biopsies at least proximal to the splenic flexure was required, as a diagnosis of CC can be missed and mistaken as LC if only biopsies from the rectum or sigmoid colon are examined. ${ }^{15-17}$ The aim was to characterise the clinical features so no clinical inclusion criteria were used. Patients with stool examinations positive for ova, parasites, Clostridium difficile toxin, Salmonella, Shigella, Campylobacter, or Yersinia were excluded, as well as patients with diarrhoea of other causes except coeliac disease or bile acid malabsorption.

\section{Histopathology and endoscopy}

The original colonic mucosal biopsy specimens were used in the reassessment. Counting of IEL was performed in haematoxylin-eosin stained samples and measurement of the subepithelial collagen layer was made in van Gieson stained specimens. If the quality of the original sections was too poor for reassessment or if the van Gieson stain was missing, new sections were made from the original paraffin wax embedded biopsy blocks. The subepithelial collagen layer was measured by an ocular micrometre in a well orientated section of the mucosa where three adjacent crypts were cut in a vertical manner and extending all the way down to the muscularis mucosae. A representative location was used for measurement. The number of IEL was calculated by counting the number of IEL per 100 epithelial cells. Only the surface epithelium was examined and areas overlying lymph follicles in the lamina propria were avoided. Counting was performed on two biopsies, if possible one from the right colon and one from the left colon, and the mean number for each patient was registered. Occurrence of occasional crypt abscesses,

Abbreviations: CC, collagenous colitis; IEL, intraepithelial lymphocytes; LC, lymphocytic colitis; MC, microscopic colitis; SeHCAT, selenium homocholic acid taurin 
cryptitis, crypt distortions, or neutrophil leucocytes in the lamina propria did not exclude the diagnosis of LC. ${ }^{11}$ The macroscopic appearance of the colonic and ileal mucosa during endoscopy was recorded.

\section{Clinical data}

All clinical data were evaluated retrospectively. The date of diagnosis was defined as the year and month when the diagnostic colonoscopy was done, and the date of onset of symptoms was when the patient first experienced symptoms. The long term course of the disease was evaluated individually in terms of single attack, chronic intermittent, or chronic continuous. In a single attack, the patient, after the first disease period, remained asymptomatic with or without maintenance therapy. A symptom free period of at least six months between two relapses was required for a chronic intermittent course. Continuous symptoms for at least six months were required for a chronic continuous course. Medication possibly related to the onset of LC was recorded in two groups; either with an association to both introduction and withdrawal of the drug or with an association only to the introduction of the drug.

\section{Laboratory data}

The following blood tests were recorded at the time of diagnosis: erythrocyte sedimentation rate, $\mathrm{C}$ reactive protein, haemoglobin, platelet concentration, alkaline phosphatase, alanine transaminase, aspartate transaminase, albumin, and creatinine. Occurrence of bile acid malabsorption was investigated by the ${ }^{75}$ selenium homocholic acid taurine (SeHCAT) test. ${ }^{18}$ A retention value of less than $10 \%$ on day 7 was considered diagnostic for bile acid malabsorption.

\section{Treatment response}

If medication improved symptoms it was registered as "effect", and as "no effect" if it had no impact on symptoms. Side effects causing withdrawal of therapy were recorded. Patients given combined therapy were excluded from this analysis. Whenever possible, duration of treatment as well as time to relapse was recorded.

\section{Statistics}

Clinical and histopathological data are presented as median (25-75 percentiles). The Mann-Whitney U test, KruskalWallis test, or $\chi^{2}$ test with Yates' correction when appropriate, were used to compare groups, and the Spearman rank correlation test for correlation analysis. A p value $<0.05$ was considered statistically significant.

\section{RESULTS}

\section{Patients}

A total of 310 patients with a prior diagnosis of LC were reported to the study. After re-evaluation, 199 (64\%) patients were included in the study and 111 were excluded (table 1). Seventy nine of the included patients were diagnosed at our

Table 1 Patients excluded from the study $(n=111)$

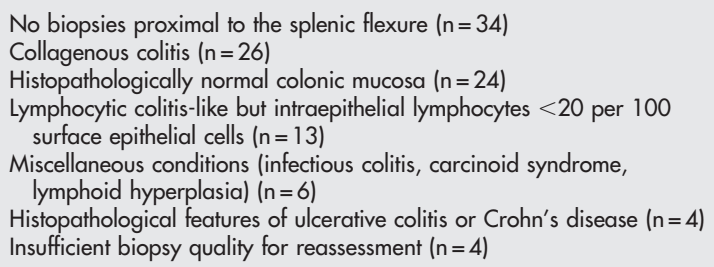

hospital. The contribution from other hospitals varied from 1 to 28 patients.

Of the 199 patients with LC, 140 were women and 59 were men, yielding a female:male ratio of 2.4:1. Age at diagnosis was 59 (48-70) years (women 58 (47-68) years and men 60 (50-73) years; $p=0.08)$. The date of onset of symptoms was recorded in 178 patients. Duration of symptoms, from onset to diagnosis, was 5 (3-12) months, with no differences between males and females $(p=0.84)$. Smoking habits at the time of diagnosis were recorded in 81 patients (table 2 ).

\section{Histopathology and endoscopy}

All patients had colonic mucosal inflammation with mainly mononuclear cells in the lamina propria as well as signs of epithelial damage. Median IEL for all patients was 39 (28-48) per 100 surface epithelial cells. In the left colon, median IEL was $36(26-48)$ compared with $39(26-52)$ in the right colon $(\mathrm{p}=0.26)$. Thirteen patients had a slightly increased subepithelial collagen layer of maximally $6-8 \mu \mathrm{m}$ while the remaining 186 patients had a normal subepithelial collagen layer. Total colonoscopy was performed in 186 patients, and 13 patients had a partial colonoscopy to the right colonic flexure or transverse colon. An ileoscopy was performed in 88 patients; all had a macroscopically normal terminal ileum. In the colon, macroscopic subtle non-specific abnormalities such as erythema, oedema, or abnormal vessel pattern were seen in 60 patients $(30 \%)$. Weight loss was reported significantly more often in these patients (33/60) compared with those with a macroscopically normal mucosa (49/139) $(\mathrm{p}=0.01)$. There were no differences regarding other clinical symptoms such as mode of onset of disease, heredity, occurrence of associated autoimmune diseases, clinical course, or number of IEL in these patients compared with those with a macroscopically normal colonic mucosa.

\section{Clinical data \\ Symptoms}

Diarrhoea was the predominant symptom and occurred in 191 patients. Eight patients had never had diarrhoea. Indications for colonoscopy in these patients were anaemia due to gastrointestinal bleeding $(\mathrm{n}=3)$, abdominal pain $(n=4)$, and a family history of colon cancer $(n=1)$. Eighteen of 191 patients with diarrhoea had 1-2 loose stools daily while the remaining had more pronounced diarrhoea with a stool frequency of 5 (4-9) stools per day. There was no correlation between the number of IEL and stool frequency at the time of diagnosis $(r=0.07, \mathrm{p}=0.42)$. Watery diarrhoea was most common and occurred in 99 patients. Thirteen patients reported blood in stools occasionally. Other common symptoms were abdominal pain $(47 \%)$ and weight loss (41\%). Median weight loss was 5 (4-8) kg (maximal $28 \mathrm{~kg}$ ). A summary of the clinical symptoms is shown in table 3 .

\section{Associated diseases}

Seventy nine patients (40\%) had at least one associated autoimmune or inflammatory disease (table 4). Age at diagnosis was not different compared with those without such a disease $(p=0.78)$. Sixty $(43 \%)$ women had an associated disease of autoimmune or inflammatory type

\begin{tabular}{|c|c|}
\hline $\begin{array}{l}\text { Current smokers } \\
\text { Former smokers } \\
\text { Never smoked }\end{array}$ & $\begin{array}{l}38(47 \%) \\
25(31 \%) \\
18(22 \%)\end{array}$ \\
\hline
\end{tabular}




\begin{tabular}{lr}
$\begin{array}{l}\text { Table } 3 \text { Clinical symptoms in } 199 \text { patients with } \\
\text { lymphocytic colitis }\end{array}$ \\
\hline Diarrhoea & $191(96 \%)$ \\
Abdominal pain & $93(47 \%)$ \\
Weight loss & $82(41 \%)$ \\
Nocturnal diarrhoea & $77(39 \%)$ \\
Sudden onset & $50(25 \%)$ \\
Fatigue & $42(21 \%)$ \\
Flatus & $30(15 \%)$ \\
Abdominal distension & $21(11 \%)$ \\
Nausea & $19(10 \%)$ \\
Faecal incontinence & $18(9 \%)$ \\
Fever & $11(6 \%)$ \\
\hline
\end{tabular}

compared with 19 men (32\%; $\mathrm{p}=0.21)$. Twenty four patients (21 women) had more than one disease. The four most frequent diagnoses were thyroid disorder $(n=31 ; 30$ women), coeliac disease ( $\mathrm{n}=17 ; 12$ women), diabetes mellitus ( $\mathrm{n}=10 ; 7$ women), and psoriasis ( $\mathrm{n}=8 ; 5$ women).

Of 17 patients with coeliac disease, eight were diagnosed before the diagnosis of LC. Six responded well to a gluten free diet and the duodenal mucosa was normalised. Because of recurrent diarrhoea, further investigation led to a diagnosis of LC a median of 11 years after the diagnosis of coeliac disease. Two patients responded partially to a gluten free diet and LC was diagnosed three years later. Coeliac disease was diagnosed simultaneously with LC in the other nine patients. Three improved on a gluten free diet but in four a gluten free diet had no effect. Another patient responded clinically well to a gluten free diet but four years later histopathology revealed unchanged villous atrophy but normalised colonic mucosa. One patient achieved clinical remission before a gluten free diet was started. Clinical remission was sustained but histopathological follow up two years later showed unchanged villous atrophy.

Depression was reported in 28 patients (14\%; 22 women) and malignancies in 17 (9\%; 13 women) patients. Four patients had been treated for colorectal cancer, three of them 5, 12, and 19 years, respectively, before the onset of LC, and one four years after. Prior to the onset of LC, appendectomy had been performed in $17 \%$ of patients, cholecystectomy in $10 \%$, and hysterectomy in $12 \%$.

\section{Clinical course and follow up}

The clinical course was evaluable in 145 patients. A single attack occurred in $63 \%$ of patients, a chronic intermittent course in $30 \%$, and a chronic continuous course in $7 \%$. Duration of a single attack from diagnosis to clinical remission was 2 (1-5) months, and from onset of symptoms to remission, 6 (4-11) months. Duration from onset to diagnosis did not predict the time to subsequent clinical remission $(r=0.08, \mathrm{p}=0.46)$.

Median follow up time for all 199 patients was 13 (437) months; in those with a single attack, 12 (4-30) months, a chronic intermittent course, 45 (24-59) months, a chronic continuous course, 20 (11-33) months, and in patients whose clinical course could not be evaluated, 6 (213) months. There was no difference between clinical courses either in the number of IEL $(p=0.75)$ or the presence of associated autoimmune or inflammatory diseases $(p=0.29)$. A follow up colonoscopy was performed in 25 patients after 25 (15-51) months. Histopathological examination showed a normal mucosa in nine patients, remaining LC in 11 patients and CC in five patients. Only one of five patients developing CC had a slightly increased subepithelial collagenous layer $(7 \mu \mathrm{m})$ when LC was diagnosed.
Table 4 Associated autoimmune or inflammatory diseases in 199 patients with lymphocytic colitis

\begin{tabular}{lc}
\hline Thyroid disorders & $31(16 \%)$ \\
Hypothyroidism & 17 \\
Hyperthyroidism & 6 \\
Goitre/thyroiditis & 8 \\
Coeliac disease & $17(9 \%)$ \\
Diabetes mellitus & $10(5 \%)$ \\
Psoriasis & $8(4 \%)$ \\
Polymyalgia rheumatica & $7(4 \%)$ \\
Asthma & $7(4 \%)$ \\
Rheumatoid arthritis & $5(3 \%)$ \\
Sarcoidosis & $3(2 \%)$ \\
Siögren's disease & $3(2 \%)$ \\
Vitiligo & $3(2 \%)$ \\
Alopecia areata & $3(2 \%)$ \\
Other* & $11(6 \%)$ \\
\hline
\end{tabular}

*Myositis $(n=2)$, iritis $(n=2)$, systemic lupus erythematosus, mixed connective tissue disease, undefined collagenosis, chronic active hepatitis, Raynaud's phenomenon, multiple sclerosis, and Guillain-Barre syndrome.

\section{Drug induced LC}

In 19 patients (10\%, 14 women), drug induced LC was suspected (table 5 ). The onset of symptoms was in between 5 days and 4 months (median 2 months) after introduction of the drug. Three patients improved within 2 weeks to I month after withdrawal of the drug, and in one patient rechallenge with carbamazepine caused recurrent diarrhoea. In 16 patients no improvement occurred after withdrawal of the drug and they required medical treatment.

\section{Month of onset of symptoms}

In this analysis, we included only patients who were diagnosed within 12 months after the onset of symptoms $(\mathrm{n}=136)$. A non-significant peak of onset of symptoms was seen in December-January $\left(\chi^{2}(11 \mathrm{df})=15.5, \mathrm{p}=0.16\right)$ (table 6).

\section{LC patients with a family history of other bowel diseases}

In $24(12 \%)$ LC patients, there was a family history of ulcerative colitis, Crohn's disease, CC, or coeliac disease, which were reported in 34 first or second degree relatives (table 7). In 14 of 24 LC patients, a family occurrence of inflammatory bowel disease was reported in 23 relatives; Crohn's disease $(n=10)$, ulcerative colitis $(n=10)$, and unspecified inflammatory bowel disease $(n=3)$. None reported a family history of LC. Age at diagnosis of the 24 LC cases with a family occurrence of other bowel diseases was 53 (41-63) years compared with 59 (48-71) years $(p=0.06)$ in those without, whereas age at diagnosis of the

\begin{tabular}{|c|c|c|}
\hline & $\begin{array}{l}\text { No of cases with an } \\
\text { association to introduction } \\
\text { and withdrawal of the } \\
\text { drug }\end{array}$ & $\begin{array}{l}\text { No of cases with } \\
\text { an association to } \\
\text { introduction of the } \\
\text { drug }\end{array}$ \\
\hline Carbamazepine & 2 & 2 \\
\hline Paroxetine & 1 & \\
\hline Sertraline & & 7 \\
\hline Ticlopidine & & 1 \\
\hline Lansoprazole & & 1 \\
\hline Penicillin V & & 1 \\
\hline Pivmecillinam & & 1 \\
\hline Simvastatin & & 1 \\
\hline Orlistate & & 1 \\
\hline Ketoprofen & & 1 \\
\hline
\end{tabular}


Table 6 Observed versus expected monthly distribution of onset of lymphocytic colitis $(n=136)^{*}$

\begin{tabular}{lll}
\hline & Observed & Expected \\
\hline January & 19 & 11.6 \\
February & 11 & 10.4 \\
March & 11 & 11.6 \\
April & 9 & 11.2 \\
May & 14 & 11.6 \\
June & 15 & 11.2 \\
July & 12 & 11.6 \\
August & 9 & 11.6 \\
September & 5 & 11.2 \\
October & 8 & 11.6 \\
November & 7 & 11.2 \\
December & 16 & 11.6 \\
\hline
\end{tabular}

$\chi_{(11 d f)}^{2}=15.5, p=0.16$.

*Only patients diagnosed within 12 months after the onset of lymphocytic colitis are included

14 LC cases with a family history of inflammatory bowel disease was $48(43-64)$ years $(p=0.1)$. Drug induced disease was reported significantly more often in patients with a family history (7/24) compared with those without (12/175) $(p=0.002)$, as well as weight loss $(16 / 24$ versus $66 / 175)$ $(p=0.01)$. No other differences were found regarding clinical symptoms, mode of onset of disease, macroscopic appearance of the colonic mucosa, laboratory results, occurrence of associated autoimmune diseases, or clinical course.

\section{Laboratory data}

Only non-specific minor abnormalities were recorded in laboratory data. Twenty one patients were investigated with the SeHCAT test. Three (14\%) had bile acid malabsorption.

\section{Treatment response}

The outcome of treatment is shown in table 8. Prednisolone was the most effective treatment but a relapse occurred in 14 of $15(93 \%)$ responding patients. Five patients relapsed during dose tapering and nine in a median of 1.5 months after withdrawal of therapy. Fourteen of 17 patients responded to budesonide. Later, three relapsed 1-7 months after withdrawal of therapy whereas six remained in clinical remission, and five patients were well on maintenance therapy for a median of 27 months with a median dose of $3 \mathrm{mg}$ daily. Twenty six of 46 patients responded to treatment with cholestyramine. The treatment effect could not be correlated with the SeHCAT results as only six patients had been investigated. Six of the 14 patients responding to metronidazole relapsed within one month after discontinuation of treatment. One patient underwent surgery with performance of a loop ileostomy which was closed after eight months due to large ileostomy output. A spontaneous remission was seen in $19(10 \%)$ patients, including three patients with drug induced disease responding to drug withdrawal.

\section{DISCUSSION}

The aetiology of LC is largely unknown. At present, LC is thought to be caused by an immunological reaction to different mucosal insults in predisposed individuals. Infectious agents, drugs, or food antigen such as gluten may be precipitating factors.

Infection with Campylobacter jejuni has been associated with the onset of LC..$^{19}$ Of special interest is the condition known as "Brainerd diarrhoea". This is outbreaks of chronic watery diarrhoea characterised by acute onset and prolonged duration, and histopathological resemblance of LC. ${ }^{20}$ Epidemiological data suggest an infectious cause of
Table 7 Distribution of diagnosis in 34 relatives of 24 of 199 lymphocytic colitis patients with a family history of ulcerative colitis, Crohn's disease, collagenous colitis, or coeliac disease

\begin{tabular}{lll}
\hline & $\begin{array}{l}\text { 1st degree } \\
\text { relative }\end{array}$ & $\begin{array}{l}\text { 2nd degree } \\
\text { relative }\end{array}$ \\
\hline Ulcerative colitis or Crohn's disease & 15 & 8 \\
Collagenous colitis & 2 & 5 \\
Coeliac disease & 4 & 5 \\
\hline
\end{tabular}

"Brainerd diarrhoea", but no causative organism has been identified. The theory of an infectious cause in some cases of LC is supported by a sudden onset in $25 \%$ of patients, and a clinical course with a single attack in $63 \%$ of cases. The nonsignificant tendency to seasonality of disease onset, and the response to metronidazole in some patients, may also support an infectious theory.

To date, at least 16 drugs have been reported with the onset of LC. ${ }^{14}{ }^{21-33}$ Ticlopidine is most often reported with more than 30 cases $^{82134}$ followed by Cyclo 3 Fort. ${ }^{23}{ }^{35}$ In most cases there has been an association with the introduction as well as with the withdrawal of the drug, and histopathological remission has in many cases followed clinical remission after drug withdrawal. In the present study, the onset of LC in three patients was associated with introduction of a drug followed by clinical remission after withdrawal. Carbamazepine was reported in two cases and paroxetine, a selective serotonin reuptake inhibitor, in one case. To our knowledge, this is the first report of paroxetine associated LC. A weaker association was seen in $16 \mathrm{LC}$ patients where an association was found only to introduction of the drug. However, patients did not improve after withdrawal of the drug and required medical treatment. The suspected drug in seven of these patients was sertraline, another selective serotonin reuptake inhibitor. It may however be difficult to obtain a correct drug history, especially regarding the use of non-steroidal anti-inflammatory drugs or proton pump inhibitors which in Sweden have been available over the counter since 1985 and 2000, respectively. This may cause underestimation of our values for drug induced disease.

The importance of genetic factors in LC is largely unknown and there are only a few reports of familial occurrence of MC. ${ }^{36-39}$ The family history of bowel diseases in our cohort of LC patients is a new and intriguing observation. Ulcerative colitis, Crohn's disease, coeliac disease, or CC was reported in 34 first or second degree relatives of 24 LC patients. A family history of ulcerative colitis or Crohn's disease was seen in 14 (7\%) LC patients compared with three of 170 (2\%) LC patients reported by Pardi and colleagues. ${ }^{13}$ We do not have the number of relatives at risk and cannot assess family risk estimates. Familial aggregation is well known in patients with ulcerative colitis or Crohn's disease, and in first degree relatives the risk of inflammatory bowel disease is increased $10-15$-fold.$^{40}$ In order to analyse the influence of genetic and/ or environmental factors, or to identify an early stage of subclinical disease, a number of subclinical markers have been analysed. Studies of intestinal permeability, antineutrophil cytoplasmic antibodies, anti-Saccharomyces cerevisiae antibodies, and faecal calprotectin have suggested, although data are not consistent, subclinical abnormalities in healthy relatives of patients with inflammatory bowel disease..$^{4-43}$ Hypothetically, an underlying common abnormality predisposing to both MC and inflammatory bowel disease may explain the association found by us.

Our patients were slightly younger at diagnosis than in most previous reports. The female:male ratio was within the 
Table 8 Retrospective evaluation of treatment responses in lymphocytic colitis

\begin{tabular}{lcccl}
\hline & No of patients & \multicolumn{1}{c}{ Effect } & No effect & Side effects \\
\hline Loperamide & 67 & $47(70 \%)$ & $17(25 \%)$ & $3(5 \%)$ \\
Bulking agents & 12 & $3(25 \%)$ & $9(75 \%)$ & 0 \\
Cholestyramine & 46 & $26(57 \%)$ & $13(28 \%)$ & $7(15 \%)$ \\
Sulphasalazine & 19 & $4(21 \%)$ & $6(32 \%)$ & $9(47 \%)$ \\
Mesalazine & 28 & $14(50 \%)$ & $11(39 \%)$ & $3(11 \%)$ \\
Olsalazine & 5 & 1 & 3 & 1 \\
Metronidazole & 23 & $14(61 \%)$ & $7(30 \%)$ & $2(9 \%)$ \\
Norfloxacin & 5 & 2 & 3 & 0 \\
Prednisolone & 16 & $15(94 \%)$ & $1(6 \%)$ & 0 \\
Budesonide & 17 & $14(82 \%)$ & $2(12 \%)$ & $1(6 \%)$ \\
\hline
\end{tabular}

previous reported ratios of $1.1: 1$ to $5.0: 1 .^{4811}{ }^{13}{ }^{14}$ Contrary to earlier studies, we did not find a higher proportion of exsmokers than current smokers ${ }^{8}{ }^{13}$ but our smoking data were uncertain considering the large number of patients with unknown smoking habits. The clinical data were consistent with the two previous largest retrospective studies. ${ }^{8}{ }^{13}$ Fernandez-Banares et al reported a higher frequency of abdominal pain, faecal incontinence, and flatulence in their LC patients, which may reflect the prospective design of their study. ${ }^{14}$ In the present study, we included patients only on histopathological criteria without taking into account clinical criteria. This allowed us to analyse the whole spectrum of clinical symptoms in cases with histopathologically proven LC. We found a small number of patients $(4 \%)$ without diarrhoea and some (9\%) who had only mild diarrhoea whereas the remaining patients had pronounced diarrhoea. LC has previously been described in patients without diarrhoea $^{79}$ and whether those patients will later develop diarrhoea is not known. Abdominal pain, weight loss that sometimes was substantial, and nocturnal diarrhoea were other common symptoms. The clinical course was similar to the results of Baert et al and Fernandez-Banares et al but differed from the data of Pardi et al whose patients all had intermittent or constant diarrhoea. ${ }^{8} 1314$

The frequency of associated diseases of the autoimmune or inflammatory type was similar to the study by Pardi and colleagues. $^{13}$ Thyroid disorders dominated, followed by coeliac disease. The relation between LC and coeliac disease is complex. Fine et al found a high prevalence of coeliac disease associated HLA-DQ genes in MC which may explain the coexistence of both coeliac disease and MC in the same

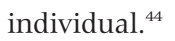

To date, no randomised controlled treatment trials have been carried out in LC, and only a few uncontrolled studies with a reasonable number of patients exist. ${ }^{13}{ }^{14}$ Corticosteroids, prednisolone, as well as budesonide were the most effective therapies in our study and $>80 \%$ of patients improved short term. However, the relapse risk was high after withdrawal of therapy. Budesonide, a topically acting corticosteroid with a high receptor binding affinity and with low systemic effects due to a high first pass metabolism in the liver, is a better alternative than prednisolone for long term treatment. ${ }^{45}$ However, controlled studies are required to address the efficacy and safety of budesonide in short term as well as in long term therapy in LC. The response rate to cholestyramine was $57 \%$, which is within previously reported rates of $46-83 \% .^{13}{ }^{14} 46$ A high frequency of patients with concomitant bile acid malabsorption in the Spanish study was probably the explanation for their high response rate of $83 \%{ }^{14}$ The outcome of 5-ASA or sulphasalazine therapy is inferior compared with the Spanish data ${ }^{14}$ but close to those of Pardi and colleagues. ${ }^{13}$ Side effects of sulphasalazine were common and similar to the occurrence in CC. ${ }^{47}$
Lymphocytic colitis and CC are considered related but separate diseases. They are clinically indistinguishable and can be differentiated only by histopathological assessment. The clinical course of LC in the present study differed from our previous study of CC where a single attack was seen in only $2 \%$ of patients, and $85 \%$ patients had a chronic intermittent course. ${ }^{47}$ Conversion of LC to CC has been reported previously and is considered to be uncommon. ${ }^{48}$ Our figures indicate that the conversion rate may be higher but a histopathological follow up of the whole material is necessary to assess this properly.

This is the largest cohort of patients with LC reported hitherto. The strength of the study is the size of the material and that all biopsy material was reassessed. Referral bias was limited as the majority of referred patients were from local hospitals and only $13 \%$ of these patients came from university hospitals. Furthermore, the severity or clinical course of the referred cases did not differ from the 79 patients from the catchment area of our own hospital (data not shown).

In summary, our data confirm previous reports regarding sex and age distribution, clinical features, associated diseases, and outcome of therapy. A single attack with clinical remission after limited disease duration was common. Drug induced disease was suspected in $10 \%$ of patients, and paroxetine causing LC has not been reported previously. The finding of a family history of other bowel disorders is new and deserves confirmation as well as the observation of a possible seasonal variation in disease onset.

\section{ACKNOWLEDGEMENTS}

The following colleagues generously submitted patient records for this study: Anne-Lie Nielsen and Hans Tanghöj (Eskilstuna); Henrik Ferling (Falun); Pierre Ahlkvist (Hudiksvall); Christer Grännö and Henrik Stjernman (Jönköping); Olof Lannerstad (Kalmar); Anders Danielsson and Dan-Axel Hallbäck (Karlskoga); Ebbe Lyrenäs (Karlskrona); Dan Hegewald and Mansor Habibi (Katrineholm); Margareta Gedin (Kristinehamn); Henrik Hamnered (Lidköping); Jan Bergman and Yeshi Yimam (Lindesberg); Magnus Ström (Linköping); Bengt Sundbaum (Luleå-Boden); Monica BergmarkHallén and Bengt-Olof Rydén (Motala); Pontus Götell (Nyköping); Ulf Lindgren (Piteå); Jorge Frones (Skene); Gudrun Schumacher and Lars Kjellström (Stockholm); Jan Linde and Michael Wedén (Södertälje); Mikael Olsson (Trollhättan); Åke Danielsson, Pontus Karling, and Henry Nyhlin (Umeå); Birgitta Hilding (Västerås).

The study was financially supported by the Örebro County Research Committee, the Örebro University Hospital Research Foundation, the Signe and Reinhold Sund's Foundation, the Swedish Society of Medicine (grant 2002-396), and the Nanna Svartz Research Grant.

\section{Authors' affiliations}

M Olesen, J Bohr, G Järnerot, C Tysk, Department of Medicine, Division of Gastroenterology, Örebro University Hospital, Örebro, Sweden S Eriksson, Department of Pathology, Örebro University Hospital, Örebro, Sweden 


\section{REFERENCES}

1 Lazenby AJ, Yardley JH, Giardiello FM, et al. Lymphocytic ("microscopic") colitis: a comparative histopathologic study with particular reference to collagenous colitis. Hum Pathol 1989;20:18-28.

2 Bohr J, Olesen M, Tysk C, et al. Collagenous and lymphocytic colitis: a clinical and histopathological review. Can J Gastroenterol 2000;14:943-7.

3 Fernandez-Banares $F$, Salas A, Forne $M$, et al. Incidence of collagenous and lymphocytic colitis: a 5-year population-based study. Am J Gastroenterol 1999;94:418-23.

4 Agnarsdottir M, Gunnlaugsson O, Orvar KB, et al. Collagenous and lymphocytic colitis in Iceland. Dig Dis Sci 2002;47:1122-8.

5 Olesen M, Eriksson S, Bohr J, et al. Microscopic colitis: a common diarrhoeal disease. An epidemiological study in Örebro, Sweden, 1993-1998. Gut 2004;52:346-50.

6 Giardiello FM, Lazenby AJ, Bayless TM, et al. Lymphocytic (microscopic) colitis. Clinicopathologic study of 18 patients and comparison to collagenous colitis. Dig Dis Sci 1989;34:1730-8.

7 Mullhaupt B, Guller U, Anabitarte M, et al. Lymphocytic colitis: clinical presentation and long term course. Gut 1998;43:629-33.

8 Baert $F$, Wouters $K, D^{\prime}$ Haens $G$, et al. Lymphocytic colitis: a distinct clinical entity? A clinicopathological confrontation of lymphocytic and collagenous colitis. Gut 1999;45:375-81.

9 Wang N, Dumot JA, Achkar E, et al. Colonic epithelial lymphocytosis without a thickened subepithelial collagen table: a clinicopathologic study of 40 cases supporting a heterogeneous entity. Am J Surg Pathol 1999;23:1068-74.

10 Bonner GF, Petras RE, Cheong DM, et al. Short-and long-term follow-up of treatment for lymphocytic and collagenous colitis. Inflamm Bowel Dis 2000;6:85-91.

11 Ayata G, lthamukkala S, Sapp H, et al. Prevalence and significance of inflammatory bowel disease-like morphologic features in collagenous and lymphocytic colitis. Am J Surg Pathol 2002;26:1414-23.

12 Kitchen PA, Levi AJ, Domizio P, et al. Microscopic colitis: the tip of the iceberg? Eur J Gastroenterol Hepatol 2002;14:1199-204.

13 Pardi DS, Ramnath VR, Loffus EV jr, et al. Lymphocytic colitis: clinical features, treatment, and outcomes. Am J Gastroenterol 2002;97:2829-33.

14 Fernandez-Banares F, Salas A, Esteve M, et al. Collagenous and lymphocytic colitis. evaluation of clinical and histological features, response to treatment, and long-term follow-up. Am J Gastroenterol 2003:98:340-7.

15 Tanaka M, Mazzoleni G, Riddell RH. Distribution of collagenous colitis: utility of flexible sigmoidoscopy. Gut 1992;33:65-70.

16 Carpenter HA, Tremaine WJ, Batts KP, et al. Sequential histologic evaluations in collagenous colitis. Correlations with disease behavior and sampling strategy. Dig Dis Sci 1992;37:1903-9.

17 Offner FA, Jao RV, Lewin KJ, et al. Collagenous colitis: a study of the distribution of morphological abnormalities and their histological detection. Hum Pathol 1999;30:451-7.

18 Merrick MV. Gall-bladder and colonic retention of SeHCAT: a re-evaluation. Eur J Nucl Med 1994;21:988-90.

19 Perk G, Ackerman Z, Cohen P, et al. Lymphocytic colitis: a clue to an infectious trigger. Scand J Gastroenterol 1999;34:110-12.

20 Bryant DA, Mintz ED, Puhr ND, et al. Colonic epithelial lymphocytosis associated with an epidemic of chronic diarrhea. Am J Surg Pathol 1996:20:1102-9.

21 Berrebi D, Sautet A, Flejou JF, et al. Ticlopidine induced colitis: a histopathological study including apoptosis. I Clin Pathol 1998;51:280-3.

22 Thomson RD, Lestina LS, Bensen SP, et al. Lansoprazole-associated microscopic colitis: a case series. Am J Gastroenterol 2002:97:2908-13.

23 Pierrugues R, Saingra B. Lymphocytic colitis and Cyclo 3 fort: 4 new cases. Gastroenterol Clin Biol 1996;20:916-17.
24 Mahajan L, Wyllie R, Goldblum J. Lymphocytic colitis in a pediatric patient: a possible adverse reaction to carbamazepine. Am J Gastroenterol 1997;92:2126-7.

25 Beaugerie L, Patey N, Brousse N. Ranitidine, diarrhoea, and lymphocytic colitis. Gut 1995:37:708-11.

26 Mennecier D, Gros P, Bronstein JA, et al. Chronic diarrhea due to lymphocytic colitis treated with piroxicam beta cyclodextrin. Presse Med 1999;28:735-7.

27 Macaigne G, Boivin JF, Chayette C, et al. Oxetorone-associated lymphocytic colitis. Gastroenterol Clin Biol 2002;26:537.

28 Rassiat E, Michiels C, Sgro C, et al. Lymphocytic colitis due to Modopar. Gastroenterol Clin Biol 2000;24:852-3.

29 Mennecier D, Saloum T, Roycourt AM, et al. Chronic diarrhea and lymphocytic colitis associated with Daflon therapy. Gastroenterol Clin Biol 1999;23:1101-2.

30 Bouchet-Laneuw F, Deplaix P, Dumollard JM, et al. Chronic diarrhea following ingestion of Tardyferon associated with lymphocytic colitis. Gastroenterol Clin Biol 1997;21:83-4.

31 Rassiat E, Michiels C, Piard F, et al. Lymphocytic colitis in a women with Biermer's disease treated with Cirkan. Presse Med 2001;30:970.

32 Piche T, Raimondi V, Schneider S, et al. Acarbose and lymphocytic colitis. Lancet 2000;356:1246.

33 Chauveau E, Prignet JM, Carloz E, et al. Lymphocytic colitis likely attributable to use of vinburnine (Cervoxan). Gastroenterol Clin Biol 1998;22:362.

34 Swine C, Cornette P, Van Pee D, et al. Ticlopidine, diarrhea and lymphocytic colitis. Gastroenterol Clin Biol 1998;22:475-6.

35 Beaugerie L, Luboinski J, Brousse N, et al. Drug induced lymphocytic colitis. Gut 1994;35:426-8.

36 Järnerot G, Hertervig E, Grännö C, et al. Familial occurrence of microscopic colitis: a report on five families. Scand J Gastroenterol 2001;36:959-62.

37 Abdo AA, Zetler PJ, Halparin LS. Familial microscopic colitis. Can J Gastroenterol 2001;15:341-3.

38 Freeman HJ. Familial occurrence of lymphocytic colitis. Can J Gastroenterol 2001; 15:757-60

39 Kong SC, Keogh S, Carter MJ, et al. Familial occurrence of microscopic colitis: an opportunity to study the relationship between microscopic colitis and coeliac disease? Scand J Gastroenterol 2002;37:1344-5.

40 Binder V. Genetic epidemiology in inflammatory bowel disease. Dig Dis 1998;16:351-5.

41 Yang H, Rotter J. The genetics of ulcerative colitis and Crohn's disease. In: Kirsner JB, ed. Inflammatory bowel disease, 5th edn. Philadelphia: WB Saunders Co, 2000:250-79

42 Thjodleifsson B, Sigthorsson G, Cariglia N, et al. Subclinical intestinal inflammation: an inherited abnormality in Crohn's disease relatives? Gastroenterology 2003;124:1728-37.

43 Tamboli CP, Richard F, Colombel JF. Fecal calprotectin in Crohn's disease: new family ties. Gastroenterology 2003; 124:1972-4.

44 Fine KD, Do K, Schulte K, et al. High prevalence of celiac sprue-like HLA-DQ genes and enteropathy in patients with the microscopic colitis syndrome. Am J Gastroenterol 2000;95:1974-82.

45 Löfberg R, Rutgeerts P, Malchow $\mathrm{H}$, et al. Budesonide prolongs time to relapse in ileal and ileocaecal Crohn's disease. A placebo controlled one year study. Gut 1996:39:82-6.

46 Ung KA, Kilander A, Willen R, et al. Role of bile acids in lymphocytic colitis. Hepatogastroenterology 2002;49:432-7.

47 Bohr J, Tysk C, Eriksson S, et al. Collagenous colitis: a retrospective study of clinical presentation and treatment in 163 patients. Gut 1996:39:846-51.

48 Giardiello FM, Lazenby AJ. The atypical colitides. Gastroenterol Clin North Am 1999;28:479-90. 